Martínez Torrecilla, Carmen Bibiana.

Investigadora, no doctora. En el grupo ARTEC (Avanced Research and Technological Expansion in Computer Graphics), en el IRTIC (Instituto de Robótica y Tecnologías de la Información y de la Comunicación) de la Universitat de València.

Pérez Aixendri, Manolo.

Profesor de Departamento de Informática de la Universitat de València. Técnico de soporte a la Investigación en el IRTIC.

Naharro Navarro, Toño.

Artista/Artesano por cuenta propia.

Tomás Marín, Toni.

Artista por cuenta propia.

\title{
Sinergias entre arte, paisaje natural y tecnología a través de "Dime algo dulce, cariño"
}

\section{Synergies between Art, natural lanscape and technology through "Tell me something sweet, sweetie"}

TIPO DE TRABAJO: Comunicación.

PALABRAS CLAVE

Sinergia, entornos sensibles, paisaje natural, paisaje virtual.

KEY WORDS

Synergy, sensitive environments, natural landscape, virtual landscape.

RESUMEN

\begin{abstract}
Las conexiones artísticas que se producen en la actualidad entre: el barro, en todo su potencial, y la tecnología electrónica y digital, en todas sus facetas, es un territorio inédito, desconocido, en el que aparece una nueva mirada salvaje, exótica desde un prisma artístico. Las sinergias que surgen, entre el material más primigenio que es el barro, dúctil por excelencia, con los materiales que definen el arte de los nuevos medios, crean nuevos espacios de experimentación e investigación en las artes visuales. Es en esta nueva correlación, es donde se sitúa la obra "Dime algo dulce cariño", presentada en la XVI Edición de ARTE EN LA TIERRA, que se celebró el pasado agosto en La Rioja. El objetivo principal de este proyecto, se enmarca en la construcción de un espacio sensible de conexión/interacción con el territorio, en el que el público se comunicara y reconectara con el planeta tierra. Para crear este vínculo con el paisaje rural, se construyó un conjunto escultórico que conformaba un espacio de diálogo y de comunicación, en el que predominó el factor humano.
\end{abstract}

ABSTRACT

The artistic connections that are currently produced between: mud, in all its potential, and electronic and digital technology, in all its facets, is an unknown territory, unknown, in which a new wild, exotic look appears from a artistic prism. The synergies that arise, between the most primitive material that is the clay, the ductile par excellence, the materials that define the art of the new media, the 


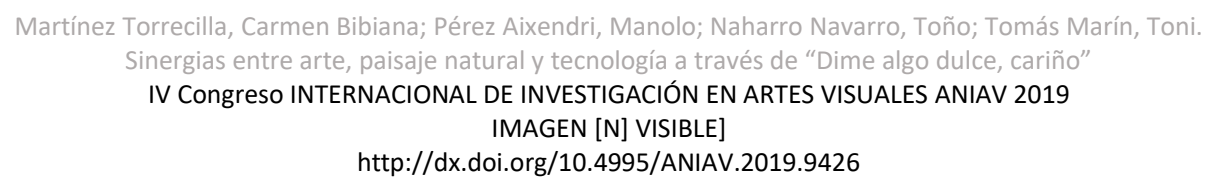

new spaces of experimentation and the investigation in the visual arts. It is in this new correlation, is where the work "Tell me something sweet love," published in the 16th Edition of ART IN THE EARTH, which was held last August in La Rioja. The main objective of this project is the search for information in the sensitive space of connection / interaction with the territory, public communication and reconstruction with the planet earth. In order to create this link with the rural landscape, a set of sculptures was built that make up a space for dialogue and communication, in which the human factor predominated.

\section{INTRODUCCIÓN}

Arte en la Tierra es un certamen internacional, de arte en la naturaleza que se celebra en Santa Lucía de Ocón. Comenzó siendo en el año 2003, una iniciativa pionera del escultor canario Felix Reyes, afincando en La Rioja, que estrenó con artistas locales. A lo largo de los años esta convocatoria ha ido evolucionando (Calonge, 2007) y la suma de su labor con la de su compañera, la artista Rosa Castellot y la comisaria Susana Baldor, ha conseguido que se convierta en un evento internacional, además de un hito artístico en el norte de la península. Conociendo el apoyo y la implicación de los habitantes del pueblo, que ceden sus campos y ayudan en la elaboración de las obras, se presentó "Dime algo dulce, cariño" a dicha cita cultural consolidada, siendo aprobada por unanimidad por el jurado.

Mencionada obra, fundamentó su investigación, en la creación de un espacio sensible de interacción, capaz de recoger las emociones de los visitantes en los mensajes que dedicaron a la tierra. Para conseguirlo, se estableció un laboratorio experimental en el que se integraron los materiales orgánicos de la zona, con tecnología básica de grabación, creando a partir de esa fusión, un espacio de comunicación sin precedente, en este acontecimiento riojano. Dicho laboratorio experimental, se desarrolló con la cooperación de los habitantes de la zona. Así como, en el proyecto "Nidos de equilibrio" de la artista Ana Laura Cantera, en el que involucra el concepto de comunidad en la realización de su obra. Construyendo en conjunto, un objetivo común, para poder coexistir con nuestro entorno natural de una forma más equilibrada, modificando nuestras prácticas en pos de la sustentabilidad (Cantera, 2015).

Por tanto, el estudio presentado, no solo explora nuevas formas de expresión e interacción situadas en un entorno natural, asimismo se beneficia de los aspectos más comunitarios de la elaboración de la obra, al crear un taller de trabajo colaborativo para su desarrollo. Este carácter le otorga un complemento y acentúa los aspectos simbólicos de la obra, en su apariencia más comunitaria, en donde se reconcilia la humanidad con la naturaleza.

\section{Fases del trabajo colaborativo para la elaboración de la obra}

Para crear esta obra, el proceso de realización se dividió en tres fases principales: la fase de proyección, la fase de producción y la fase de posproducción.

Para diseñar la fase de proyección, se forjó un equipo colaborativo de trabajo con: el escultor Toni Tomás y el alfarero contemporáneo Toño Naharro, y la artista Bibiana Martínez. En esta fase, se bocetaron el conjunto de esculturas de gran formato que iban a configurar el círculo totémico, con formas inspiradas en antiguos respiraderos naturales de bodegas de la zona. Se calcularon los tamaños, los materiales y los tiempos de elaboración, así como el ajuste de los gastos, al presupuesto conseguido.

En la siguiente fase, la de producción, se desarrolló durante una semana de convivencia. Esta parte fue coordinada por todo el equipo de artistas, y pudo ser resuelta por la ayuda de más de 30 personas de la zona (Figura1). El escultor Toni Tomás había creado las estructuras de los seis volúmenes soldando varillas de hierro, que definió con la escala humana y paisajista adecuada. Posteriormente se pasó a cubrir las estructuras de hierro, con una especie de "vestido", formados por malla metálica y tela de arpillera, a los que el artista Toño Naharro adaptó la tonelada de barro en polvo, que había recopilado de los cuatro puntos cardinales de la región. Una vez cubiertas todas las estructuras, el artista Naharro se encontró con 70 metros lineales para poder expresarse con pigmentos, trazos, dibujos tribales, con los caracteres que determinan su obra. 


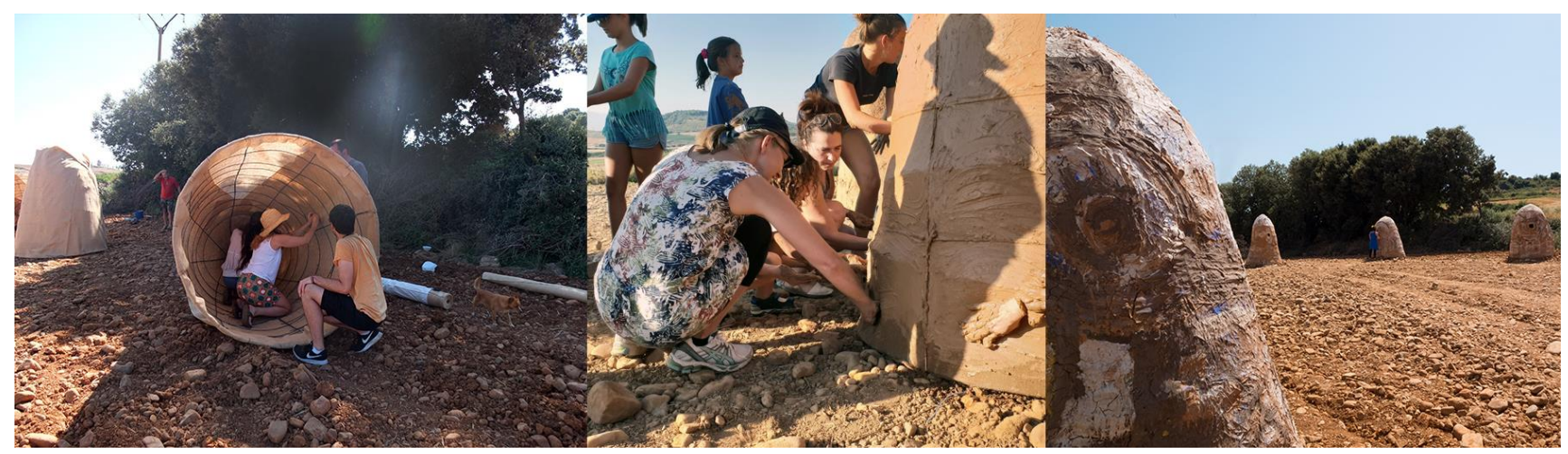

Figura 1. Imágenes de la fase de producción de la obra. Elaboración propia.

Por último, Bibiana Martínez integró las grabadoras de audio en el interior de tres de los tótems, que con anterioridad habían sido preparadas, por el técnico de investigación Manolo Pérez, en los laboratorios del IRTIC de la Universitat de València (Figura2).

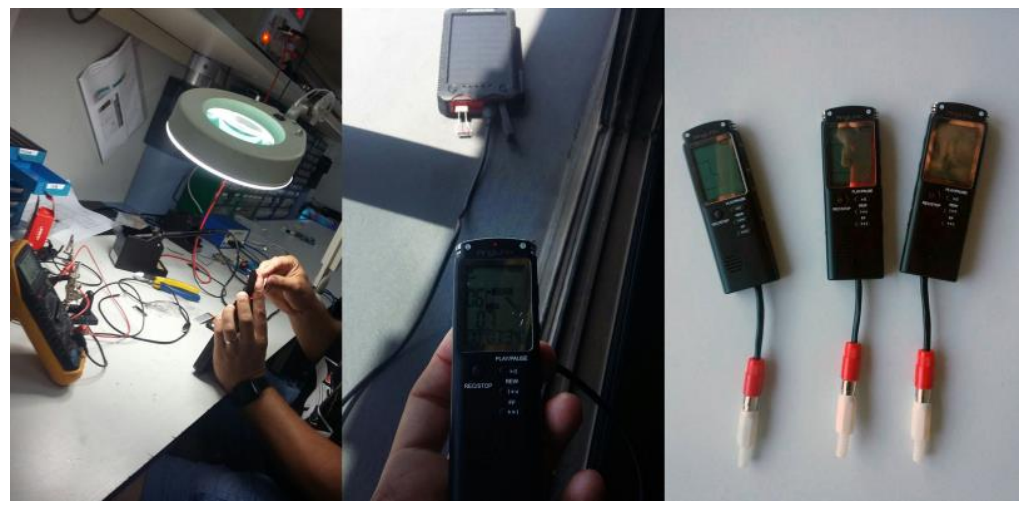

Figura 2. Imágenes del trabajo realizado con las grabadoras. Elaboración propia.

Para realizar las grabaciones de los mensajes, incluimos en los tótems, grabadoras de bolsillo modificadas para poder realizar grabaciones durante todo el periodo de exposición. Las grabadoras contaban con una memoria de 8Gb cada una y con inicio de grabación automático al detectar sonido. Esto permitía que el espacio de almacenamiento fuera suficiente puesto que, durante gran parte del día la grabadora permanecería inactiva. El principal problema a salvar era la duración de la batería. Se descartó la posibilidad de enchufarlas a un cargador puesto que no había corriente donde se realizaría la instalación. Se pensó en realizar una carga solar. Se realizaron pruebas con distintas placas solares que generaran el voltaje necesario para las placas, pero el presupuesto no permitió obtener intensidad suficiente para cargar los dispositivos. La solución final pasó por alimentar las placas mediante una batería de coche. La batería entrega $12 \mathrm{~V}$ mientras que las grabadoras necesitan $5 \mathrm{~V}$ por lo que añadimos al circuito un regulador de voltaje para ajustar a los valores adecuados. Dado el bajo consumo de las grabadoras y la alta capacidad de carga de la batería de coche, el sistema pudo mantenerse autónomo durante todo el periodo de exposición.

Y por último la fase de posproducción, en esta parte Bibiana Martínez edita el material recopilado en las grabaciones, en los laboratorios de ARTEC. Posteriormente son incorporados en dos lugares distintos: en la exposición que se realizó en ESDIR la Escuela de Diseño de la Ciudad de Logroño, el pasado mes de febrero. Se escuchaban los mensajes a la tierra como sonido de fondo de la exposición. La segunda en la ubicación de los mensajes de voz, es en la web (https://www.uv.es/bibiana/dimealgodulcecarinyo/index.html), después de bocetar en 3D y texturizar el grupo escultórico e integrarlo en un entorno virtual, estos modelos junto a los mensajes registrados, se integraron en la plataforma de trabajo en tiempo real Unity ${ }^{1}$, donde se generó una interacción sencilla con el paisaje virtual.

\footnotetext{
1 Unity 3D es una herramienta que nos ayuda a desarrollar videojuegos para diversas plataformas mediante un editor y scripting para crear videojuegos con un acabado profesional. (https://unity.com/)
} 


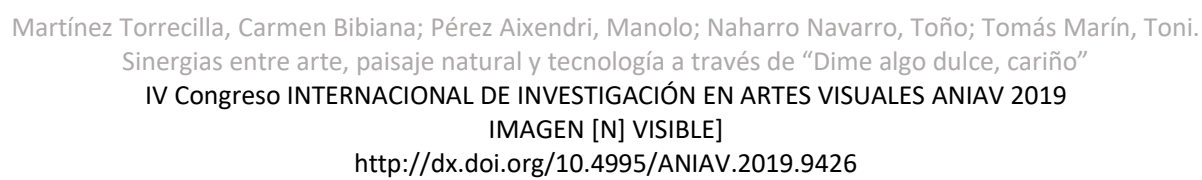

\section{METODOLOGÍA}

El objetivo principal, de la obra que presentamos en esta investigación, era crear un espacio comunicación con el planeta tierra, un ambiente de conexión en el que se propiciara una interaccion emotiva del espectador. En la que se reflejara, por un lado, una sensación de permanencia espacio-temporal del lugar, una evocación de familiriadad con las formas totémicas y por otro parte, un efecto de fuerza de la naturaleza, trasgrendiendo la vision de ese paisaje rural cotidiano, con el que conviven los habitantes de la comarca.

Para conseguir este espacio sensible de comunicación, hemos nutrido nuestra investigación de varias fuentes, una de ellas sería: el modus operandi del equipo artístico Studio Azzurro: el grupo de carácter colaborativo de artistas de nuevos medios, fundado en 1982 por Fabio Cirifino, Paolo Rosa y Leonardo Sangiorgi en Milán. Sus obras generan reflexiones teóricas y planteamientos éticos, habitats artísticos en donde el público participa, no solo como espectador si no como co-artífice, convirtiéndose en parte primordial de la obra. El diseño del proyecto "Dime algo dulce, cariño" se basó concretamente, en el estudio de la exposición AMBIENTES SENSIBLES que

presentó en la Sala Parpalló de la ciudad de Valencia en el año 2008. En dicha muestra expusieron "entornos sensibles", "interfaces naturales" que desaparecen como obra quedando en la memoria como experiencias vividas (Molina, 2008). Estas líneas de trabajo, determinan uno de los objetivos de esta investigación artística como: la búsqueda de un espacio de actuación en la que se elimine la tecnología de la visión del espectador, para crear una interacción espontánea sin artificios, en el que la obra se convierta en espacioambiente-escena en el que prevalezca el factor humano.

Otra de las fuentes en las que está basada esta investigación es la obra de la artista Eve Ariza presentada en la Bienal de Venecia del 2017, titulada "Murmuri". Una instalación elaborada artesanalmente, para la que se tornearon 9.500 boles de barro. Estos miles de contenedores no funcionales, colocados a modo de mural en la pared, actuaban como receptores de murmullos, de sonidos que facilitaba el visitante. A partir de una forma milenaria, como es el recipiente, la artista andorrana crea una auténtica experiencia sensorial, con un lenguaje universal. Liberando del contenido narrativo tradicional al barro, la obra provoca de entrada, un diálogo físico con el espectador. Por lo que, la esencia utilitaria del objeto desaparece y su forma sencilla se transforma en verdadero símbolo de la conexión interhumana (Ambatlle, 2017). Percibiendo esta fuerte capacidad del material en la obra de Ariza, hemos propuesto en esta investigación la transformación del barro, en un material de diálogo y de conexión con el público. Y el trabajo manual/físico como un lugar de encuentro de cohesión y de comunicación.

\section{DESARROLLO}

El visitante fué informado con anterioridad, de que podía dejar mensajes a la tierra, y en el caso de lo que hiciera, estos podían ser registrados. De todos modos, en algún caso el espectador de forma intuitiva, se acercaba para dejar su mensaje, a las bocas comunicadoras que se habían acoplado a tres de los totems. Estos orificios se habian integrado con la intención de abrir una ventana con el espacio interior de la pieza. Característica que originó que las esculturas se convirtieran en canales de comunicación y que se estableciera una interacción con la obra, mucho más natural y espontánea. Se colocaron la grabadoras de bolsillo con sensor de voz en el interior de los volumenes a la altura de las aperturas, así estas pudieron registrar de una forma más nítida los sonidos. Asímismo, desaparecieron de la vista del espectador, lo que convertia el espacio de interacción en un ambiente sin artificios centrando la atención en el paisaje natural intervenido (Figura 3).

Los mensajes de voz, los murmullos, los ruidos que envolvían el espacio de "Dime algo dulce, cariño" de Santa Lucía Ocón, son el resultado de la investigación presentada en este Congreso de ANIAV 2019. Estos serían la consencuencia de la interacción y se podrían catalogar, analizando los sentimientos y las sensaciones, que acontecieron en el espectador en el momento de reconectarse con la tierra y hablar con ella. La temática de los mensajes, ha sido de algún modo, encauzada por el título de la intervención paisajistica y ha abarcado desde: saludos de cortesía, saludos de reverencia, agradecimientos, una gran cantidad de comunicados de amor y de cariño a la tierra y a la población de Santa Lucía en concreto, hasta cantos de esperanza y de ánimos al medio ambiente, peticiones de disculpas, de ayuda y de deseos, como si dirigieran a la diosa de la naturaleza con poderes sobrenaturales. 
Martínez Torrecilla, Carmen Bibiana; Pérez Aixendri, Manolo; Naharro Navarro, Toño; Tomás Marín, Toni.

Sinergias entre arte, paisaje natural y tecnología a través de "Dime algo dulce, cariño"

IV Congreso INTERNACIONAL DE INVESTIGACIÓN EN ARTES VISUALES ANIAV 2019 IMAGEN [N] VISIBLE]

http://dx.doi.org/10.4995/ANIAV.2019.9426

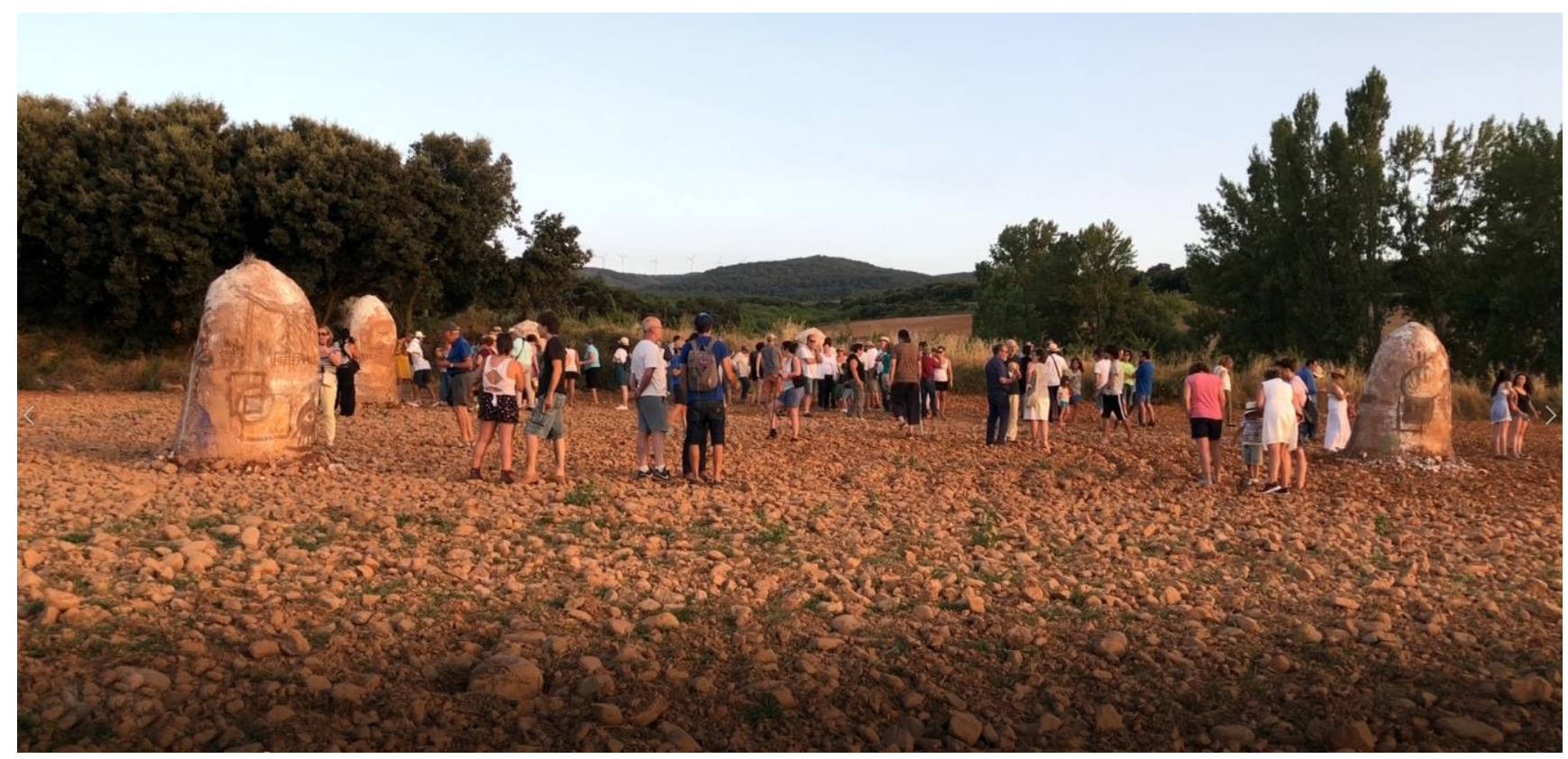

Figura 3. Captura del video realizado por el artista Demetrio Navaridas, que documentó ARTE EN LA TIERRA 2018.

\section{CONCLUSIONES}

Transformamos con "Dime algo dulce, cariño" la visión del horizonte de Santa Lucía de Ocón, situando un conjunto escultórico de gran formato, en un campo de labranza que cedió un lugareño. Creamos un espacio interacción, una experiencia estética efímera e intangible, eliminando la tecnología de la vista de los espectadores; logrando con ello, crear un entorno sensible de interacción, en el que el visitante se reconectara a la tierra y de una manera espontánea se comunicara con ella, dejándole un mensaje de voz.

Situando esta obra en el paisaje rural, rehumanizamos el territorio con la ayuda del pueblo, abanderando con esta acción la defensa del patrimonio natural y cultural. Por lo que, con "Dime algo dulce, cariño" reivindicamos el paisaje creando conciencia ecológica, a partir del vínculo de afectos entre: los lugareños, la tierra y los sentimientos que le profesan. Por lo tanto, reutilizamos los sentimientos del pueblo hacia su entorno, como base para crear esta topofilia ${ }^{2}$ del paisaje, como uno de los criterios que sirven para conservar un lugar. En este estudio llegamos al entendimiento de que la reivindicación moderna del paisaje puede ser una de las claves para la reformulación de la conciencia ecológica, la base de una nueva cultura de vuelta a la naturaleza (Astibia, 2016).

\section{FUENTES REFERENCIALES}

Ambatlle, M. (2017). MURMURI. Pabellón de Andorra. 57 Bienal de arte Venecia. Principado de Andorra. 2077.

Astibia, H. (2016). Sobre el paisaje y su relación con el arte y la naturaleza. Euskonews (Eusko Ikaskuntza - Sociedad de Estudios Vascos), 708. ISSN 1139-3629.

Calonge, M. (2007). Poesía visual en las tierras de Santa Lucía. Belezos: Revista de cultura popular y tradiciones de La Rioja, № 5, 4-15. Fundación Caja Rioja. ISSN 1886-4333.

Cantera, A. (2015). CO-CREACIONES HIBRIDAS: Horizontalidad y relaciones entre la naturaleza y el hombre, desde el arte, las nuevas tecnologías y el desarrollo sustentable. Universidad Nacional de Tres de Febrero, Argentina.

Molina F, A. (2008). Studio Azzurro. Ambientes sensibles. Sala Parpalló, Valencia. Diputación de Valencia. Sala Parpalló, 2008. ISSN 978-84-7795-498-9.

\footnotetext{
${ }^{2}$ En este caso, la topofilia del paisaje, sería una forma de establecer relaciones emotivas entre pobladores y el paisaje rural que habitan.
} 